\title{
Tissue-engineered constructs for peripheral nerve repair: current research concepts and future perspectives
}

\author{
Alba C. de Luca1, Wassim Raffoul2 ${ }^{2}$, Francesco Giacalone ${ }^{3}$, Maddalena Bertolini ${ }^{3}$, \\ Pietro G. di Summa ${ }^{2,3}$ \\ ${ }^{1}$ EPFL, Centre for Neuroprosthetics, Laboratory for Soft Bioelectronic Interfaces, 1015 Lausanne, Switzerland. \\ ${ }^{2}$ Department of Plastic, Reconstructive and Hand Surgery, University Hospital of Lausanne (Centre Hospitalier Universitaire Vaudois), \\ 1011 Lausanne, Switzerland. \\ ${ }^{3}$ Department of Hand Surgery and Microsurgery, CTO-Maria Adelaide Trauma Center, 10126 Torino, Italy.
}

Address for correspondence: Dr. Pietro G. di Summa, Department of Plastic, Reconstructive and Hand Surgery, University Hospital of Lausanne (Centre Hospitalier Universitaire Vaudois), 1011 Lausanne, Switzerland. E-mail: pietro.di-summa@chuv.ch

\begin{abstract}
Traumatic injuries resulting in peripheral nerve lesions lead to important morbidity with devastating social and economic consequences. When the lesioned nerve cannot be sutured directly, a nerve graft is generally required to bridge the gap. Although autologous nerve grafting is still the first choice for reconstruction, it has the severe disadvantage of the sacrifice of a functional nerve. Research in tissue engineering and nerve regeneration may have a dramatic impact on clinical and surgical treatment of such nerve lesions. The authors review the latest concepts in tissue engineering for nerve repair, including scaffold engineering of neural guides, biomaterial modification, cell therapy, growth factors delivery, and electrical stimulation. Recent literature is reviewed in detail, pointing out the most interesting present achievements and perspectives for future clinical translation. Electronic search of the literature was performed using MEDLINE, Embase, and the Cochrane Library to identify research studies on peripheral nerve regeneration through tissue-engineered conduits. The following medical subject headings were used to carry out a systematic search of the literature: "nerve regeneration", "stem cells", "biomaterial", "extracellular matrix", "functional regeneration", "growth factors" and "microchannels". Included literature was published between 1991 and 2014. The reference lists from the retrieved articles were also reviewed for additional articles. In total, 76 articles were included in this study.
\end{abstract}

Key words:

Cell transplantation, extracellular matrix, growth factors, nerve guidance conduit, peripheral nerve repair, surface modification

\section{INTRODUCTION}

The success of repair after peripheral nerve injury depends on the type and the extension of the trauma. In the event of nerve compression or sheath loss, the structural elements in the nerve tissue are preserved,

\begin{tabular}{|l|l|}
\multicolumn{2}{|c|}{ Access this article online } \\
\hline Quick Response Code: & Website: \\
\hline & www.parjournal.net \\
\hline & \\
\hline
\end{tabular}

and injury recovery can occur without surgery. However, severe trauma can cause the complete disruption of the nerve (neurotmesis), resulting in the complete loss of continuity and function. ${ }^{[1]}$

The two segments generated after nerve transection retract, and edema occurs at the distal stump. The latter starts to swell and degenerates within hours in a process known as "Wallerian degeneration". ${ }^{2]}$ The regeneration process takes place at the proximal stump, where the axon soma is still included, forming the growth cone that expands toward the distal stump to bridge the gap.

When nerves are severed, and denervation occurs, the longer the lag time reinnervation, the worse the functional recovery. ${ }^{[3]}$ Long denervation time, as clinically seen in 
brachial plexus injuries, causes complete atrophy of target tissues, followed by fibrosis and fragmentation of motor fibers.

The current "gold standard" in peripheral nerve surgeries is an autograft, which is defined as the interposition of autologous nerve segments (typically from the leg or the forearm). Despite the ideal core structure provided by the autologous tissue transferred, autografts allow only partial functional recovery, involve double surgery and cause donor tissue morbidity, calling for tissue engineered solutions to overcome these inconveniences.

A nerve guidance conduit (NGC) is a valid alternative to autograft, providing a confined environment for the entire regenerative process. NGC can be made of both natural and artificial materials. Its chemical and physical properties can be optimized to achieve the best performance in terms of tissue regeneration and inflammatory response, as illustrated by several reviews. ${ }^{[4-6]}$ However, despite the number of proposed engineered materials, the functional recovery after conduit repair of peripheral nerve injuries still fails where long $(>3 \mathrm{~cm})$ gaps are created.

In the last decade, researchers have focused on different approaches to control and guide the regeneration of the injured tissue. The most promising options will be discussed below, including modification of the inner lumen architecture, transplantation of glial/stem cells (SCs), inclusion of extracellular matrix (ECM) components and neurotrophic factors [Figure 1].

\section{INTRALUMINAL ARCHITECTURE}

The importance of designing new NGC has been raised in the last decade. Topography of the inner lumen can dramatically affect the ability of both the nerve to regenerate across the gap and the endogenous cells to migrate and proliferate along the structure to modulate production and release of neurotrophic factors. Using

\begin{tabular}{|c|c|}
\hline $\begin{array}{l}\text { Intraluminal Architecture } \\
\text { Wall modifications } \\
\text { - Micro-Nano grooves } \\
\text { - Pillars } \\
\text { - Electrospinning } \\
\text { Intraluminal aligned fibers } \\
\text { Microchannels }\end{array}$ & 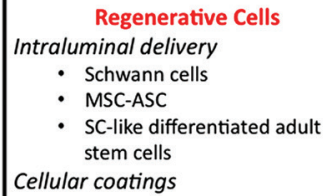 \\
\hline
\end{tabular}

\begin{tabular}{|c|c|}
\hline $\begin{array}{l}\text { Tissue er } \\
\text { to regen }\end{array}$ & $\begin{array}{l}\text { approach } \\
\text { ve guides }\end{array}$ \\
\hline $\begin{array}{l}\text { Extracellular Matrix } \\
\text { Wall Coatings } \\
\text { - LM, FN, Fibrin, Collagens } \\
\text { - ECM Peptides } \\
\text { Intraluminal ECM fillers, Hydrogels }\end{array}$ & \begin{tabular}{|l} 
Growth factors \\
NGF, $B D N F, N T s$, GDNF, FGF, NRG-1 \\
- Lumen delivery \\
- Encapsulation \\
- Diffusion \\
- Controlled release
\end{tabular} \\
\hline
\end{tabular}

Figure 1: Different tissue engineering approaches to improve nerve conduits for peripheral nerve regeneration. MSC: Mesenchymal adult stem cells, ASC: Adipose-derived adult stem cells, LM: Laminin, FN: Fibronectin, ECM: Extra cellular matrix, NGF: Nerve growth factor, BDNF: Brain-derived neurotrophic factor, NTs: Neurotrophins, GDNF: Glial-derived neurotrophic factor, FGF: Fibroblast growth factor, NRG-1: Neuregulin 1 features from micro- to nanoscale, several surface modifications have been performed in order to simulate the organized native structure of the neuronal tissue, including micro- or nanogrooves to direct SC and neurite alignments in a mechanism also known as "conduct guidance", micro-pits and pillars. ${ }^{[7,8]}$ Microgrooves triggered SC alignment and migration along the pattern direction, ${ }^{[9-11]}$ simulating the organized structure of the glial cells when forming the bands of Büngner. Another technique commonly used to recreate longitudinal patterns in the conduit lumen is electrospinning, which allows the fabrication of micro- or nanofibrous conduits. Nerve conduits fabricated with electrospun aligned fibers influence cell migration and nerve fiber alignment after regeneration. ${ }^{[7]}$ Aligned micro- ${ }^{[12]}$ and submicro- ${ }^{[13]}$ electrospun fibers were compared to a random fiber configuration in an in vivo study, with the oriented topography stimulating axon outgrowth and glial cell migration along the direction of the fibers. Moreover, variations in fiber diameter and distribution have been shown to affect both the permeability and the porosity of the neural tube, finally influencing cell response. ${ }^{[4]}$

A different approach to alter the architecture of nerve conduit guidance is to fill the empty tube with oriented intraluminal frameworks or filaments, characterized by a larger total surface area compared to a bare conduit. However, these fillers may hinder the regenerative process, and it is necessary to accurately control their "packing density" and distribution, which may have a large impact on the final ability of the nerve to regenerate.

Thin films of polyacrylonitrile-co-methyl acrylate composed of aligned fibers were inserted into the lumen of polysulfone conduits and compared to randomly aligned fibers and smooth films in a short-term in vivo study using a rat model..$^{[14]}$ Nerve regeneration was accelerated in conduits containing the aligned fibrous film, resulting in higher levels of myelination and muscle reinnervation when compared to the other groups. This could be due to a high directionality and alignment of endogenous SC, which are involved in the formation of the new tissue and the myelination of the regenerated axons.

Microchannel elongating across the length of the tube is an alternative lumen modification to guide axonal growth in a confined environment. Agarose multi-channel conduits were shown to allow axonal growth after injury, and vascularization occurred after 10 weeks in vivo. ${ }^{[15]}$ In a recent study, a silicon-based conduit containing 24 micro-fabricated parallel channels with a diameter of $130 \mu \mathrm{m}$ allowed the regeneration of the nerve across the injury gap in a rat model, resulting in $85 \%$ axon myelination. ${ }^{[16]}$ It was demonstrated that innervation was unsuccessful at the external ring of the concentric microchannels while all the remaining channels were filled with neuronal tissue and blood vessels. When cells were preloaded in microchannel conduits, the internal guides also helped the seeding and increased the availability of the cells, with enhanced outcomes. ${ }^{[17]}$ Interestingly, when similar multichannel structures were created with fibrin, 
no differences in terms of regeneration between numbers and diameters of the channels were observed. ${ }^{[18]}$

In addition to providing a physical path for the regenerative process, microchannels also act as "axonal signal amplifiers" when applied in nerve stimulating-recording devices. The electrical resistance of the intracellular medium is increased by the constricted environment, and the recorded signal of the extracellular potential is therefore amplified when specific electrodes are embedded in the structure, according to Fitzgerald et al., ${ }^{[19]}$ Microelectrodes arrays are in fact commonly used to record neural activity during the regeneration process at the injury site. New technological frontiers have allowed researchers to fabricate stretchable electrodes to better conform and deform along the tubular nerve conduit, responding more anatomically to the physical stress which conduits undergo in vivo and reducing the inflammatory response. ${ }^{[16,20]}$

\section{INFLUENCE OF EXTRACELLULAR MATRIX MOLECULES AND FILLERS}

Peripheral nerves have the potential to regenerate after injury, as opposed to the central nervous system. This is mainly attributed to the presence of SC basement membranes rich in ECM components, such as laminin (LM) and fibronectin $(\mathrm{FN})$, which promote axonal regeneration in the peripheral nervous system. The ECM milieu of the regenerating nerve is not simply a passive scaffold for regrowth, as its molecules can synergistically signal with growth factors and growth cone molecules to influence regrowth. ${ }^{[21]} \mathrm{LM}$, fibrin, FN and collagen are the main ECM proteins used as coatings for peripheral nerve repair. ECM molecules such as $\mathrm{LM}^{[22]} \mathrm{FN}^{[23,24]}$ and collagen ${ }^{[25]}$ have been shown to enhance axonal regeneration when incorporated into nerve guidance channels. ${ }^{[26]}$

Alternatively, FN- and LM-derived peptide moieties, such as RGD (Arg-Gly-Asp), , ${ }^{[27,28]}$ IKVAV (Ile-Lys-Val-Ala-Val), ${ }^{[29,30]}$ and YIGSR (Tyr-Ile-Gly-Ser-Arg), ${ }^{[31]}$ have been recognized to trigger specific interactions between neural cells and the accordingly modified substrate.

Different from coatings, ECM proteins have been used for the formation of gels or matrices as intraluminal fillers of NGCs, such as fibrin gels, shown interesting results in terms of regeneration. ${ }^{[32]}$ However, this ECM protein maintains SC in a nonmyelinating state $\mathrm{e}^{[33]}$ and therefore, the degradation time of the gel should be optimized in order to trigger axon myelination in due time during regeneration.

Another composite hydrogel containing collagen and hyaluronan, with or without growth factors, was used in combination with poly(L-lactide-co-caprolactone). ${ }^{[34]}$ Both the compound muscle action potential and the muscle recovery were improved when compared to the empty control, while no differences were observed in presence or absence of nerve growth factor (NGF).

For a detailed review on the effect of ECM components on peripheral nerve regeneration, readers are advised to consult a recent publication. ${ }^{[35]}$

\section{CELLTRANSPLANTATION}

Cell-based therapy is considered a valid approach to stimulate and enhance the regeneration of the injured nerve, overcoming the delayed recruitment and response of endogenous SC at the injury site, and therefore reducing their progressive atrophy in vivo. SC have been either injected at the injury site or preseeded in the nerve conduit, ${ }^{[36,37]}$ with high rates of successful axon regeneration and myelination. In addition, various growth factors expression in SC can be induced as needed for the specific purpose. Prior studies have presented successful transfections of SC with either fibroblast growth factor $(\mathrm{FGF})^{[38]}$ or $\mathrm{NGF}^{[39]}$ both stimulating nerve repair in an injury rat model. Recently, SCs were transplanted ex vivo before implantation in order to investigate the impact of brain-derived nerve factor (BDNF), ciliary neurotrophic factor (CNTF), and neurotrophin 3 (NT-3) on nerve regeneration and recovery. The result was a significant improvement of axon outgrowth and myelination, ${ }^{[40]}$ with cells remaining viable for up to 8 weeks in vivo. However, the harvest of autologous SC involves a significantly debilitating biopsy from the patient. In addition, SC adhesion and proliferation are considerably slower when compared to cells cultured in vitro (requiring for instance the precoating of each culture substrate), resulting in long culture time in order to achieve a suitable number for therapeutic uses.

Stem cells have become very attractive in tissue engineering and regenerative medicine due to their ability to self-renew and differentiate into most cell

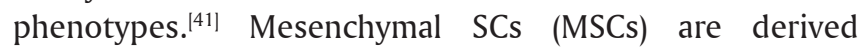
from bone marrow stromal progenitors and have been demonstrated to be able to trans-differentiate into several cell lineages, including osteoblasts, chondrocytes, endothelial cells, myocytes, neurons, and glial cells. In particular, when MSC are differentiated into SC-like cells, they are able to express the characteristic glial markers and enhance peripheral nerve regeneration in vivo by improving myelination of axons and increasing regeneration distances. ${ }^{\mid 42]}$

Undifferentiated MSC was preseeded in a chitosan conduit in an in vivo study for 6 weeks using a rat model, with successful regeneration similar to autografting. ${ }^{[17]}$ In addition, these cells were used in a monkey model to repair a $50-\mathrm{mm}$ median nerve defect in a long-term in vivo experiment. ${ }^{[43]}$ Cells were injected directly after implantation at the proximal stump to overcome the deficit of local SC, resulting in enhanced regenerative properties compared to the nonseeded conduits. Similar outcomes comparable to autografts were then assessed in a dog model, bridging a $50-\mathrm{mm}$ sciatic nerve gap with successful muscle reinnervation. ${ }^{[4]}$ Signs of local transdifferentiation into an SC-like phenotype were observed after 8 weeks postimplantation by Oliveira et al., ${ }^{\mid 45]}$ resulting in higher formation of myelinated and unmyelinated axons, as well as blood vessels, when compared to empty conduits. 
Alternatively, SCs can be isolated from white adipose tissue using liposuction to avoid invasive procedures. ${ }^{[46,47]}$ Like MSC, adipose-derived SCs (ASCs) are able to differentiate into a SC phenotype, and their characteristic elongated spindle-shaped morphology has been confirmed through microscopy. ${ }^{[47-49]}$ Their ability to express specific glial-markers, that is, S-100, p75 and glial fibrillary acidic protein, ${ }^{[50,51]}$ as well as the protein P0 responsible for the myelin formation, ${ }^{[51]}$ has also been demonstrated. Finally, differentiated ASC (dASC) are able to express the neuronal-associated protein nestin, ${ }^{[48,50,51]}$ as well as the neuron-specific enolase and the neuron-specific protein. ${ }^{[48]}$

When undifferentiated ASC were preloaded in polycaprolactone conduits to investigate their effect on axonal outgrowth, it was observed that they were able to prevent neuron apoptosis by up-regulating the expression of anti-apoptotic BCL-2 and down-regulating the expression of caspase and BAX. ${ }^{[52]}$ These results were comparable to $\mathrm{N}$-acetylcysteine treatments, which guarantee the preservation of cell signaling and survival as previously demonstrated. ${ }^{[53-55]}$ Both ASC and dASC have been frequently used for transplantation in NGC to repair injury gaps, although different and sometimes conflicting results have been observed due to the various experimental conditions. ${ }^{[56-59]}$ Signs of in vivo transdifferentiation of undifferentiated SCs into an SC-like phenotype have been also observed, further stimulating interest in using ASC for peripheral nerve repair. ${ }^{[59]}$ However, depending on the scaffold used, the viability of the preloaded cells can be strongly affected, reducing the initial beneficial effect of the cell therapy. ${ }^{[56]}$ All of these results suggest the potential use of ASC (or dASC) in peripheral nerve repair, substituting SC.

The ultimate strategy in cell therapy is the formation of tissue engineered nerve grafts with the application of a intraluminal "cellular coating" composed of co-cultured SC and dorsal root ganglia, which are able to release and up-regulate the production of neurotrophic factors in the lumen over time. Long-term results of up to 12 weeks have shown a significant ability to regenerate the nerve comparable to nerve grafts. ${ }^{[60]}$ An even more advanced development would be the fabrication of scaffoldless neural conduits providing a confined environment without using polymeric structures, as proposed by Adams et al., ${ }^{[61]}$ In their study, their group attempted to construct a nerve guide using a monolayer of ASC differentiated into fibroblasts co-cultured with neurospheres. This system supported the in vivo expression of growth factors, such as FGF, ascorbic acid, epidermal growth factor, and transforming growth factor (TGF)- $\beta 1$, which induced the transdifferentiation of the SCs into SC-like cells. ${ }^{\mid 61]}$

\section{GROWTH FACTORS ANDTHEIR RELEASE IN NERVE GUIDANCE CONDUIT}

Neurotrophic factors belong to the family of growth factors, and they are produced by SCs during Wallerian degeneration after injury. ${ }^{[62]}$ Acting through their receptors, neurotrophic factors are involved in the neuronal activity, promoting nerve regeneration. ${ }^{[63,64]}$ In addition, their expression is strictly dependent on time after axotomy, which biases the regenerative capacity of axons, as well as the supporting activity of SCs. ${ }^{[3]}$

Neurotrophins constitute one of the most important family of factors, including NGF, BDNF, NT-3, and NT-4/5. ${ }^{[65]}$ After release, a density gradient of factors is formed around regenerating axons. ${ }^{[62]} \mathrm{NGF}$ is the one of the most important NTs involved in nerve regeneration and is up-regulated rapidly in the distal stump after injury. ${ }^{[66]}$ It is able to promote the survival and outgrowth of sensory neurons, although NGFs are not involved in the motor neuron response. ${ }^{[65]}$ BDNF is up-regulated in denervated SCs in order to allow myelination and nerve regeneration. ${ }^{[66]}$ It is involved in the outgrowth of both sensory and motor neurons. ${ }^{[62,65]}$ Finally, NT-3 and NT-4/5 promote survival of both motor and sensory neurons.

Besides NTs, other neurotrophic factors are involved in the regenerative process of nerves. CNTF is a neurokine protein down-regulated after injury, ${ }^{[65]}$ implicated in motor neuron survival, ${ }^{\mid 63]}$ outgrowth and sprouting. ${ }^{[65]}$ Moreover, glial cell line-derived neurotrophic factor (GDNF), ${ }^{[64,66]}$ $\mathrm{FGF}^{[62,65]}$ neuregulin-1, ${ }^{[64,66]}$ and leukemia inhibitory factor $^{[63,64]}$ also play an important role in peripheral nerve regeneration. Finally, TGF- $\beta$ is necessary for the nonmyelinating status of SCs during the proliferation process. ${ }^{[64]}$ Nevertheless, all neurotrophic factors described above co-operate in order to enable neuron survival and axonal outgrowth. ${ }^{[63]}$

Following injury, axotomy conditions and chronic denervation cause a reduced availability of neurotrophic factors and their supplement at the injury site is needed to stimulate and support regeneration..$^{[3,67]}$ As reviewed by Pfister et al., ${ }^{[68]}$ growth factors can be released into the lumen through different mechanisms of drug delivery from an empty conduit (i.e. dissolution in a solution, encapsulation in the conduit wall, diffusion through microspheres) or by use of an intraluminal filler (i.e. microfiber impregnation, binding and release in a matrix). However, results reported in the literature are sometimes contradictory, and optimization of their concentration and the release mechanism is, therefore, necessary. In addition, due to their low stability in solution, growth factors need to be protected when encapsulated or bond to a substrate in order to prevent their degradation and prolong their activity in situ. In fact, some ECM molecules can form specific bonds with growth factors, preserving their functionality. For example, it was found that binding to heparin or heparin sulfate can specifically stabilize FGF, GDNF, and NGF, which are then gradually released in the delivery system. ${ }^{[68]}$ Furthermore, polymer coatings of the surface of the loaded biomaterial or microsphere with polylactide-co-glycolide $e^{[12,69-71]}$ can protect and gradually control the neurotrophic factor delivery over time.

Gordon's group has extensively investigated the role of neurotrophic factors in nerve regeneration, particularly focusing on the effect of BDNF and GDNF in the system. 
Neurotrophic factors were supplemented at the injury site using a mini-osmotic pump and no effect was observed at low doses. ${ }^{[3]}$ Conversely, very high concentrations of BDNF inhibited the axonal regeneration, with a mechanism that seemed to be dose-dependent. In addition, a combination of BDNF and GDNF resulted in better nerve repair. ${ }^{[3]}$ Madduri et al. ${ }^{[70,71]}$ tested instead the efficiency of cross-linked NGF and GDNF as single growth factors or in combination to repair peripheral nerve injuries, resulting in enhanced early regeneration after two weeks postimplantation and higher SC migration. Since neurotrophic factors are gradually released in the regenerative environment by cells as a response to the natural events occurring during Wallerian degeneration and axon regeneration and myelination, it may be beneficial to recreate a molecular gradient along the inner surface of the NGC, guaranteeing the necessary supply of factors to support the regeneration process. An in vitro study demonstrated that a patterned gradient of immobilized NGF on chitosan substrates would increase axon sprouting and branching in the direction of the gradient itself. ${ }^{[13]}$ Tang et al. ${ }^{[72]}$ were also able to control the gradient distribution of NGF along a poly( $\varepsilon$-caprolactone)-block-p oly(L-lactic acid-co- $\varepsilon$-caprolactone) conduit and observed a higher sciatic function index (SFI) when compared to uniform distribution of the neurotrophic factor.

The ECM-matrix inclusion of growth factors that are gradually released in the inner lumen of the NGCs have also been considered to be a valuable alternative for the optimization of the bioengineered construct. A successful study was presented by Cao et al. ${ }^{[73]}$ during which collagen scaffolds were loaded with an LM filler containing CNTF, promoting high levels of myelination after twelve weeks postimplantation and enhancing both SFI and nerve conduction velocity.

Cell transduction can also be thought of as an alternative approach to release specific growth factors at the site of regeneration. Godinho et al. ${ }^{[40]}$ implanted peripheral nerve grafts containing SC expressing BDNF, CTNF, and NT-3, respectively, resulting in different outcomes as a function of the growth factor. Following accurate locomotor investigation by using the gait analysis system Catwalk $^{\circledR},{ }^{[74-76]}$ they showed a significant improvement of functional recovery under CTNF and NT-3 conditions while NT-3 stimulated a higher degree of myelination. ${ }^{[40]}$

\section{CONCLUSION AND FUTURE DIRECTIONS}

Despite advancements in microsurgical techniques, nerve repair clinically provides suboptimal results, and autologous nerve grafts are the primary choice for nerve reconstruction, especially over long gaps. This opens the field for research and the development of tissue engineered nerve guides [Figure 1]. The transplant of regenerative cells into biodegradable conduits could be a clinical tool translating into improved regeneration. In our experience, ${ }^{[47,49,58]}$ ASCs contribute to axonal regeneration and myelination with the improvement of functional outcomes in long-term experiments. Given their abundance and plasticity, we personally consider these cells to be one of the main options in future nerve repair studies. In this review, we have attempted to present a complete tableau of the different components which we believe are relevant for successful regeneration. To perform at their best, transplanted cells need a favorable environment, with proper attachment to biomaterials and directionality driven through conduits. If present, the external delivery of growth factors should be controlled to avoid inhibitory effects on regeneration. This would support both transplanted and native Schwann cell performance, improving nerve regeneration. The stronger mechanical stability shown by cells seeded on an ECM such as FN and LM may be essential for cell migration and control of local signaling environment. ${ }^{[36]}$ The influence of cell behavior on material coatings is an interesting question, as this effect is not dependent upon an external delivery source (as in the case of growth factors). Similarly, interactions between cells and biomaterials may influence cell performance and directionality, making it an interesting field for future research.

\section{ACKNOWLEDGMENTS}

The authors are grateful to the Swiss National Found for supporting their current research. P.G. di Summa is thankful to the SICPA foundation and the University Hospital of Lausanne (CHUV) for supporting his hand surgery training and research in peripheral nerve injury and regeneration.

\section{REFERENCES}

I. Burnett MG, Zager EL. Pathophysiology of peripheral nerve injury: a brief review. Neurosurg Focus 2004; 16:EI.

2. Geuna S, Raimondo S, Ronchi G, Di Scipio F, Tos P, Czaja K, Fornaro M. Chapter 3: histology of the peripheral nerve and changes occurring during nerve regeneration. Int Rev Neurobiol 2009;87:27-46.

3. Gordon T. The role of neurotrophic factors in nerve regeneration. Neurosurg Focus 2009;26:E3.

4. Daly W, Yao L, Zeugolis D, Windebank A, Pandit A. A biomaterials approach to peripheral nerve regeneration: bridging the peripheral nerve gap and enhancing functional recovery. J $R$ Soc Interface 20I2;9:202-2I.

5. Geuna S, Tos P, Titolo P, Ciclamini D, Beningo T, Battiston B. Update on nerve repair by biological tubulization. J Brachial Plex Peripher Nerve Inj 20 I4;9: I-6.

6. Nectow AR, Marra KG, Kaplan DL. Biomaterials for the development of peripheral nerve guidance conduits. Tissue Eng Part B Rev 2012;18:40-50.

7. Hoffman-Kim D, Mitchel JA, Bellamkonda RV. Topography, cell response, and nerve regeneration. Annu Rev Biomed Eng 2010;12:203-31.

8. Cunha C, Panseri S, Antonini S. Emerging nanotechnology approaches in tissue engineering for peripheral nerve regeneration. Nanomedicine 201 I;7:50-9.

9. Sun M, McGowan M, Kingham PJ, Terenghi G, Downes S. Novel thin-walled nerve conduit with microgrooved surface patterns for enhanced peripheral nerve repair. J Mater Sci Mater Med 2010;21:2765-74.

10. Mitchel JA, Hoffman-Kim D. Cellular scale anisotropic topography guides Schwann cell motility. Plos One 20II;6:e243I6.

II. Mobasseri SA, Terenghi G, Downes S. Micro-structural geometry of thin films intended for the inner lumen of nerve conduits affects nerve repair. J Mater Sci Mater Med 2013;24:1639-47.

12. Madduri S, Papaloizos M, Gander B. Trophically and topographically functionalized silk fibroin nerve conduits for guided peripheral nerve regeneration. Biomaterials 2010;31:2323-34.

13. Yu LM, Miller FD, Shoichet MS. The use of immobilized neurotrophins to support neuron survival and guide nerve fiber growth in compartmentalized chambers. Biomaterials 2010;31:6987-99.

14. Mukhatyar V, Pai B, Clements I, Srinivasan A, Huber R, Mehta A, 
Mukhopadaya S, Rudra S, Patel G, Karumbaiah L, Bellamkonda R. Molecular sequelae of topographically guided peripheral nerve repair. Ann Biomed Eng 2014;42:1436-55.

15. Tansey KE, Seifert JL, Botterman B, Delgado MR, Romero MI. Peripheral nerve repair through multi-luminal biosynthetic implants. Ann Biomed Eng 2011;39:1815-28.

16. FitzGerald J, Lago N, Benmerah S, Serra J, Watling CP, Cameron RE, Tarte E, Lacour SP, McMahon SB, Fawcett JW. A regenerative microchannel neural interface for recording from and stimulating peripheral axons in vivo. J Neural Eng 2012;9:016010.

17. Zheng L, Cui HF. Enhancement of nerve regeneration along a chitosan conduit combined with bone marrow mesenchymal stem cells. J Mater Sci Mater Med 2012;23:2291-302.

18. Scott JB, Afshari M, Kotek R, Saul JM. The promotion of axon extension in vitro using polymer-templated fibrin scaffolds. Biomaterials 20I I;32:4830-9.

19. Fitzgerald JJ, Lacour SP, McMahon SB, Fawcett JW. Microchannels as axonal amplifiers. IEEE Trans Biomed Eng 2008;55: I I 36-46.

20. Lacour SP, Benmerah S, Tarte E, FitzGerald J, Serra J, McMahon S, Fawcett J, Graudejus O, Yu Z, Morrison B 3rd. Flexible and stretchable micro-electrodes for in vitro and in vivo neural interfaces. Med Biol Eng Comput 2010;48:945-54.

21. Yanagida H, Tanaka J, Maruo S. Immunocytochemical localization of a cell adhesion molecule, integrin alpha5beta I, in nerve growth cones. J Orthop Sci 1999;4:353-60.

22. Buettner HM, Pittman RN. Quantitative effects of laminin concentration on neurite outgrowth in vitro. Dev Biol 1991;145:266-76.

23. Whitworth IH, Brown RA, Dore C, Green CJ, Terenghi G. Orientated mats of fibronectin as a conduit material for use in peripheral nerve repair. J Hand Surg Br 1995;20:429-36.

24. Tom VJ, Doller CM, Malouf AT, Silver J. Astrocyte-associated fibronectin is critical for axonal regeneration in adult white matter. $J$ Neurosci 2004;24:9282-90.

25. Woolford TJ, Toriumi DM. The enhancement of nerve regeneration using growth factors: a brief review. J Long Term Eff Med Implants 1995;5:19-26.

26. Labrador RO, Buti $M$, Navarro $X$. Influence of collagen and laminin gels concentration on nerve regeneration after resection and tube repair. Exp Neurol 1998; 149:243-52.

27. de Luca AC, Faroni A, Downes S, Terenghi G. Differentiated adipose-derived stem cells act synergistically with RGD-modified surfaces to improve neurite outgrowth in a co-culture model. J Tissue Eng Regen Med 2013;DOI: 10.1002/ term. 1804.

28. de Luca AC, Stevens JS, Schroeder SL, Guilbaud JB, Saiani A, Downes S, Terenghi G. Immobilization of cell-binding peptides on poly-epsilon-caprolactone film surface to biomimic the peripheral nervous system. J Biomed Mater Res A 2013;101:491-501.

29. Wei YT, Tian WM, Yu X, Cui FZ, Hou SP, Xu QY. Hyaluronic acid hydrogels with IKVAV peptides for tissue repair and axonal regeneration in an injured rat brain. Biomed Mater 2007;2:SI42-6.

30. Hosseinkhani H, Hiraoka Y, Li CH, Chen YR, Yu DS, Hong PD, Ou KL. Engineering three-dimensional collagen-IKVAV matrix to mimic neural microenvironment. ACS Chem Neurosci 2013;4:1229-35.

31. Masaeli E, Wieringa PA, Morshed M, Nasr-Esfahani MH, Sadri S, van Blitterswijk CA, Moroni L. Peptide functionalized polyhydroxyalkanoate nanofibrous scaffolds enhance Schwann cells activity. Nanomedicine 2014;10:1559-69.

32. Kalbermatten DF, Kingham PJ, Mahay D, Mantovani C, Pettersson J, Raffoul W, Balcin H, Pierer G, Terenghi G. Fibrin matrix for suspension of regenerative cells in an artificial nerve conduit. J Plast Reconstr Aesthet Surg 2008;61:669-75.

33. Akassoglou K, Yu WM, Akpinar P, Strickland S. Fibrin inhibits peripheral nerve remyelination by regulating Schwann cell differentiation. Neuron 2002;33:86I-75.

34. Jin J, Limburg S, Joshi SK, Landman R, Park M, Zhang Q, Kim HT, Kuo AC. Peripheral nerve repair in rats using composite hydrogel-filled aligned nanofiber conduits with incorporated nerve growth factor. Tissue Eng Part A 2013;19:2138-46.

35. de Luca AC, Lacour SP, Raffoul W, di Summa PG. Extracellular matrix components in peripheral nerve repair: how to affect neural cellular response and nerve regeneration? Neural Regen Res 2014;9:1943-8.

36. di Summa PG, Kalbermatten DF, Raffoul W, Terenghi G, Kingham PJ. Extracellular matrix molecules enhance the neurotrophic effect of Schwann cell-like differentiated adipose-derived stem cells and increase cell survival under stress conditions. Tissue Eng Part A 2013;19:368-79.

37. Berrocal YA, Almeida VW, Gupta R, Levi AD. Transplantation of Schwann cells in a collagen tube for the repair of large, segmental peripheral nerve defects in rats. J Neurosurg 2013;119:720-32.
38. Haastert K, Lipokatic E, Fischer M, Timmer M, Grothe C. Differentially promoted peripheral nerve regeneration by grafted Schwann cells over-expressing different FGF-2 isoforms. Neurobiol Dis 2006;2I:138-53.

39. Tannemaat MR, Verhaagen J, Malessy M. The application of viral vectors to enhance regeneration after peripheral nerve repair. Neurol Res 2008;30:1039-46.

40. Godinho MJ, Lip T, Pollett MA, Goodman D, Hodgetts SI, Sweetman I, Walters M, Verhaagen J, Plant GW, Harvey AR. Immunohistochemical, ultrastructural and functional analysis of axonal regeneration through peripheral nerve grafts containing Schwann cells expressing BDNF, CNTF or NT3. Plos One 2013;8:e69987.

4I. Tohill M, Terenghi G. Stem-cell plasticity and therapy for injuries of the peripheral nervous system. Biotechnol Appl Biochem 2004;40: 17-24.

42. Keilhoff G, Goihl A, Stang F, Wolf G, Fansa H. Peripheral nerve tissue engineering: autologous Schwann cells vs. transdifferentiated mesenchymal stem cells. Tissue Eng Part A 2006; 12:1451-65.

43. Hu N, Wu H, Xue C, Gong Y, Wu J, Xiao Z, Yang Y, Ding F, Gu X. Long-term outcome of the repair of $50 \mathrm{~mm}$ long median nerve defects in rhesus monkeys with marrow mesenchymal stem cells-containing, chitosan-based tissue engineered nerve grafts. Biomaterials 20I3;34:100-II.

44. Ding F, Wu J, Yang Y, Hu W, Zhu Q, Tang X, Liu J, Gu X. Use of tissue-engineered nerve grafts consisting of a chitosan/poly(lactic-co-glycolic acid)-based scaffold included with bone marrow mesenchymal cells for bridging 50-mm dog sciatic nerve gaps. Tissue Eng Part A 2010;16:3779-90.

45. Oliveira JT, Almeida FM, Biancalana A, Baptista AF, Tomaz MA, Melo PA, Martinez AM. Mesenchymal stem cells in a polycaprolactone conduit enhance median-nerve regeneration, prevent decrease of creatine phosphokinase levels in muscle, and improve functional recovery in mice. Neuroscience 2010; 170:1295-303.

46. Zuk PA, Zhu M, Mizuno H, Huang J, Futrell JW, Katz AJ, Benhaim P, Lorenz HP, Hedrick MH. Multilineage cells from human adipose tissue: implications for cell-based therapies. Tissue Eng Part A 200 I;7:2I I-28.

47. Kingham PJ, Kalbermatten DF, Mahay D, Armstrong SJ, Wiberg M, Terenghi G. Adipose-derived stem cells differentiate into a Schwann cell phenotype and promote neurite outgrowth in vitro. Exp Neurol 2007;207:267-74.

48. Strem BM, Hicok KC, Zhu M, Wulur I, Alfonso Z, Schreiber RE, Fraser JK, Hedrick MH. Multipotential differentiation of adipose tissue-derived stem cells. Keio J Med 2005;54:I32-4I.

49. di Summa PG, Kingham PJ, Raffoul W, Wiberg M, Terenghi G, Kalbermatten DF. Adipose-derived stem cells enhance peripheral nerve regeneration. J Plast Reconstr Aesthet Surg 2010;63:1544-52.

50. Gimble J, Guilak F. Adipose-derived adult stem cells: isolation, characterization, and differentiation potential. Cytotherapy 2003;5:362-9.

5I. Xu Y, Liu L, Li Y, Zhou C, Xiong F, Liu Z, Gu R, Hou X, Zhang C. Myelin-forming ability of Schwann cell-like cells induced from rat adipose-derived stem cells in vitro. Brain Res 2008; 1239:49-55.

52. Reid AJ, Sun M, Wiberg M, Downes S, Terenghi G, Kingham PJ. Nerve repair with adipose-derived stem cells protects dorsal root ganglia neurons from apoptosis. Neuroscience 201 I; 199:5I5-22.

53. Hart AM, Terenghi G, Kellerth JO, Wiberg M. Sensory neuroprotection, mitochondrial preservation, and therapeutic potential of $\mathrm{N}$-acetyl-cysteine after nerve injury. Neuroscience 2004; I25:91-101.

54. Welin D, Novikova LN, Wiberg M, Kellerth JO, Novikov LN. Effects of $\mathrm{N}$-acetyl-cysteine on the survival and regeneration of sural sensory neurons in adult rats. Brain Res 2009; $1287: 58-66$.

55. Reid AJ, Shawcross SG, Hamilton AE, Wiberg M, Terenghi G. N-acetylcysteine alters apoptotic gene expression in axotomised primary sensory afferent subpopulations. Neurosci Res 2009;65: |48-55.

56. Erba P, Mantovani C, Kalbermatten DF, Pierer G, Terenghi G, Kingham PJ. Regeneration potential and survival of transplanted undifferentiated adipose tissue-derived stem cells in peripheral nerve conduits. J Plast Reconstr Aesthet Surg 2010;63:e8I I-7.

57. Shen CC, Yang YC, Liu BS. Peripheral nerve repair of transplanted undifferentiated adipose tissue-derived stem cells in a biodegradable reinforced nerve conduit. J Biomed Mater Res A 20I2; 100:48-63.

58. di Summa PG, Kalbermatten DF, Pralong E, Raffoul W, Kingham PJ, Terenghi G. Long-term in vivo regeneration of peripheral nerves through bioengineered nerve grafts. Neuroscience 201।;181:278-91.

59. Orbay H, Uysal AC, Hyakusoku H, Mizuno H. Differentiated and undifferentiated adipose-derived stem cells improve function in rats with peripheral nerve gaps. J Plast Reconstr Aesthet Surg 20I 2;65:657-64.

60. Tang X, Xue C, Wang Y, Ding F, Yang Y, Gu X. Bridging peripheral nerve defects with a tissue engineered nerve graft composed of an in vitro cultured nerve equivalent and a silk fibroin-based scaffold. Biomaterials 20I2;33:3860-7. 
61. Adams AM, Arruda EM, Larkin LM. Use of adipose-derived stem cells to fabricate scaffoldless tissue-engineered neural conduits in vitro. Neuroscience 2012;20I:349-56.

62. Ide C. Peripheral nerve regeneration. Neurosci Res 1996;25:I0I-2I.

63. Terenghi G. Peripheral nerve regeneration and neurotrophic factors. J Anat 1999;194:1-14.

64. Chen ZL, Yu WM, Strickland S. Peripheral regeneration. Annu Rev Neurosci 2007;30:209-33.

65. Schmidt CE, Leach JB. Neural tissue engineering: strategies for repair and regeneration. Annu Rev Biomed Eng 2003;5:293-347.

66. Kingham PJ, Terenghi G. Bioengineered nerve regeneration and muscle reinnervation. J Anat 2006;209:5 II-26.

67. Gordon T, Tyreman N, Raji MA. The basis for diminished functional recovery after delayed peripheral nerve repair. J Neurosci 20 I 1;31:5325-34.

68. Pfister LA, Papaloizos M, Merkle HP, Gander B. Nerve conduits and growth factor delivery in peripheral nerve repair. J Peripher Nerv Syst 2007; 1 2:65-82.

69. Yang Y, De Laporte L, Rives CB, Jang JH, Lin WC, Shull KR, Shea LD. Neurotrophin releasing single and multiple lumen nerve conduits. J Control Release 2005; 104:433-46.

70. Madduri S, di Summa P, Papaloizos M, Kalbermatten D, Gander B. Effect of controlled co-delivery of synergistic neurotrophic factors on early nerve regeneration in rats. Biomaterials 2010;31:8402-9.

71. Madduri S, Feldman K, Tervoort T, Papaloizos M, Gander B. Collagen nerve conduits releasing the neurotrophic factors GDNF and NGF. J Control Release 2010;143:168-74.
72. Tang S, Zhu J, Xu Y, Xiang AP, Jiang MH, Quan D. The effects of gradients of nerve growth factor immobilized PCLA scaffolds on neurite outgrowth in vitro and peripheral nerve regeneration in rats. Biomaterials 20I3;34:7086-96.

73. Cao J, Sun C, Zhao H, Xiao Z, Chen B, Gao J, Zheng T, Wu W, Wu S, Wang J, Dai J. The use of laminin modified linear ordered collagen scaffolds loaded with laminin-binding ciliary neurotrophic factor for sciatic nerve regeneration in rats. Biomaterials 201 I;32:3939-48.

74. Hamers PT, Lankhorst AJ, Van Laar TJ, Veldhuis WB, Gispen WH. Automated quantitative gait analysis during overground locomotin in the rat: its application to spinal cord contusion and transection injuries. J Neurotrauma 200I;| I8: |87-20I.

75. Bozkurt A, Deumens R, Scheffel J, O'Dey DM, Weis J, Joosten EA, Fuhrmann T, Brook GA, Pallua N. CatWalk gait analysis in assessment of functional recovery after sciatic nerve injury. J Neurosci Methods 2008; I73:91-8.

76. Deumens R, Jaken RJ, Marcus MA, Joosten EA. The CatWalk gait analysis in assessment of both dynamic and static gait changes after adult rat sciatic nerve resection. J Neurosci Methods 2007; 164:120-30.

How to cite this article: de Luca AC, Raffoul W, Giacalone F, Bertolini M, di Summa PG. Tissue-engineered constructs for peripheral nerve repair: current research concepts and future perspectives. Plast Aesthet Res 2015;2:213-9.

Source of Support: Nil, Conflict of Interest: None declared.

Received: 01-02-2015; Accepted: 17-04-2015 